\title{
A relevância do ensino de línguas estrangeiras na formação de policiais em Moçambique
}

\author{
Alexandre António Timbane"
}

\section{Resumo}

As línguas estrangeiras têm sido as mais requisitadas no mundo globalizado. A pesquisa lança um debate sobre a metodologia do ensino e a importância das línguas no trabalho da polícia em Moçambique. A pesquisa tem por objetivos discutir o conceito língua e explicar a sua importância na formação policial; apontar metodologias que possam melhorar a qualidade de ensino e aprendizagem de línguas estrangeiras na polícia. Utilizando método bibliográfico, a pesquisa conclui que há necessidade de formação de agentes de polícia em línguas estrangeiras para que possam responder com qualidade os desafios da globalização, garantindo a ordem e tranquilidade públicas.

Palavras-chave: Ensino. Formação policial. Línguas estrangeiras. Moçambique.

\section{Introdução}

Moçambique é um país africano, localizado geograficamente no sul do continente habitado na sua maioria por povos de origem bantu. É um país multicultural e sobretudo, multilíngue com 17 línguas bantu padronizadas ortograficamente, tal como os estudos de Ngunga e Faquir (2011) apontam. Os estudos e as descrições sobre as línguas bantu moçambicanas ainda continuam e a Universidade Eduardo Mondlane tem feito diversas pesquisas que descrevem

\footnotetext{
Realizou pós-doutorado em Estudos Ortográficos na Universidade Estadual Paulista Júlio de Mesquita Filho (Unesp) (2015) e pós-doutorado em Linguística Forense na Universidade Federal de Santa Catarina (UFSC) (2014). Doutor em Linguística e Língua Portuguesa (2013) pela Unesp. Mestre em Linguística e Literatura moçambicana (2009) pela Universidade Eduardo Mondlane (UEM), Moçambique. Licenciado e bacharel em Ensino de Francês como Língua Estrangeira (2005) pela Universidade Pedagógica (UP), Moçambique. Professor adjunto da Universidade de Integração Internacional da Lusofonia Afro-Brasileira (Unilab), Campus dos Malês, BA. E-mail: alextimbana@gmail.com
}

Data de submissão: jul. 2017 - Data de aceite: jan. 2018 http://dx.doi.org/10.5335/rdes.v14i1.7287 
e classificam essas línguas incluindo a separação entre dialetos e variantes. Por essa razão é difícil dizer de forma categórica quantas línguas existem em Moçambique.

As línguas bantu moçambicanas são faladas pela maioria da população, sendo $89,3 \%$ de falantes a falam como sua língua materna, segundo dados do Recenseamento Geral da População e Habitação realizado em 2007. Dados do Recenseamento populacional de 2017 estão sendo processados pelo Instituto Nacional de Estatística, mas os resultados preliminares apontam para um crescimento populacional de cerca de 20.5 milhões em 2007 para 28.9 milhões em 2017. É importante referir que o número de falantes de línguas bantu tende a reduzir devido à política linguística do país que oficializou apenas o português desde 1975, ano da independência do jugo colonial português.

Para Cristal (2003), uma língua pode ser tornada a língua oficial de um país, para ser usada como um meio de comunicação em domínios como o governo, os tribunais, os meios de comunicação e o sistema educacional. Para avançar nessas sociedades, é essencial dominar a língua oficial o mais cedo possível. $\mathrm{E}$ entende-se que a oficialização de qualquer que seja a língua de uma nação depende de boas práticas da política e do planejamento linguístico (CALVET, 2012). Não existe uma língua pobre, incapaz e selvagem que não possa permitir a plena comunicação na comunidade.
Todas as línguas do mundo (ágrafas ou não) podem exprimir o pensamento e emoções dos seus usuários. No caso de Moçambique, a língua oficial (língua portuguesa) é de origem europeia e é muitas vezes descrita como uma segunda língua, porque é vista como um complemento à língua materna, ou primeira língua (CRISTAL, 2003). Quem não conhece a língua oficial fica desprovido dos séricos básicos, fica em desvantagem na justiça, na educação, na saúde e em outros serviços.

Segundo Timbane (2015), a língua portuguesa é de prestígio por ser oficial e amparada pela Constituição da República de Moçambique (CRM) de 2004. A CRM dá pouca relevância às línguas bantu moçambicanas faladas pela maioria da população. A maior parte da população habita nas zonas rurais e fala as diversas línguas bantu. Para além destas línguas africanas, Moçambique conta com cinco línguas de origem asiática: gujarate, memane, hindu, urdo e o árabe faladas por comunidades asiáticas radicadas no país e pela comunidade islã e muçulmana enraizada principalmente na região norte de Moçambique. É importante referir que existe uma língua de sinais que é, na verdade, pouco difundida devido ao preconceito linguístico enraizado pela cultura.

Todos os países que fazem fronteira com Moçambique (exceto Madagascar) são de expressão inglesa, nomeadamente: a Suazilândia, a África do Sul, o Zimbábue, a Zâmbia (a oeste) e a Tanzânia 
(à norte). Esta situação geolinguística coloca Moçambique numa 'ilha' linguisticamente, pois o vizinho linguístico mais próximo é a República de Angola (capital Luanda) que dista $3.682 \mathrm{~km}$ da capital - Maputo.

O isolamento linguístico de Moçambique provocada pela localização geográfica incentivou a aceitação de organizações como Commonwealth, Organização Internacional da Francofonia, Organização da Conferência Islâmica. Esta integração tem interesses econômicos e políticos para além de linguísticos. Por essa razão, as línguas inglesa e francesa são disciplinas obrigatórias nos ensinos fundamental, médio e técnico de Moçambique.

A política linguística determinou que o português seria a única língua oficial, o que significa que as cerca de vinte línguas bantu (faladas pela maioria da população) não possuem nenhum valor de prestígio, sendo assim usadas em situações de comunicações informais e longe da elite e das oportunidades. Uma das justificativas da oficialização apenas do português é o fato de existir no país várias línguas, o que dificultaria a escolha das oficiais. Não concordamos com este ponto de vista porque as línguas bantu moçambicanas seriam oficiais nos locais onde elas ocorrem. No Brasil, por exemplo, as línguas indígenas tukano, baniwa e nheengatu são línguas oficiais no município de São Gabriel da Cachoeira, no Amazonas e essa atitude não cria divergências políticas e nem étnicas.
Não estamos afirmando que o Brasil é um bom exemplo nessa política. Ainda existem muitas línguas indígenas da família tupi-guarani que estão em vias de extinção devido à tomada de decisões políticas erradas. Mas a atitude tomada em São Gabriel da Cachoeira em Amazonas é positiva e por isso aqui elogiamos. AÁfrica do Sul é um exemplo mais contundente da oficialização das línguas locais, pois conseguiu oficializar 11 línguas, nomeadamente: ndebele, xhosa, zulu, sesoto, tswana, suazi, venda, tsonga, africânder, sepedi e inglês (NEVILLE, 2004).

Portanto, não se trata de incapacidade linguística para que as línguas locais sejam oficiais, mas sim a vontade política, pois existem inúmeros exemplos no mundo onde se oficializou as línguas locais e essa atitude preservou/ preserva as línguas da extinção, deu/dá autoestima aos falantes e às comunidades, para além de preservar esse bem que é patrimônio cultural. Por outro lado, Moçambique e os moçambicanos são aliciados por línguas estrangeiras que prometem 'mundos e fundos' para quem deseja desenvolver na vida econômica o que do nosso ponto de vista não constitui verdade. A sociedade atual é muito exigente e sempre privilegia as línguas estrangeiras como alavanca para o sucesso, o que em muitos casos não corresponde à verdade.

Por outro lado, a língua inglesa tem obtido um espaço mais privilegiado no mundo, como a língua da política, das 
tecnologias e da economia. O domínio do Inglaterra, dos Estados Unidos e da Austrália impulsiona cada vez mais a importância do inglês no espaço global. Os Estados Unidos criam pressão para todo continente americano (e por que não para o mundo), a Inglaterra cria pressão na Europa, a Austrália cria pressão na Ásia. No continente africano, o inglês ganha força graças à herança colonial, uma vez que todas as colônias britânicas oficializaram o inglês como língua oficial. No mundo 63 países, segundo Calvet (2012), adotaram o inglês como oficial. Em contrapartida, o francês foi oficializado em 36 países diferentes (CALVET, 2012). Para Rodrigues,

[...] a língua inglesa padrão constitui capital imprescindível para a mobilidade social nas ex-colônias britânicas da África, mas se restringe, no entanto, no processo, as línguas maternas são estigmatizadas pelos próprios falantes, que as veem como obstáculo à ascensão econômica e social (2011, p. 119).

O número de falantes de inglês tende a crescer em todo mundo, resultado de políticas e da necessidade de ascensão dos povos (principalmente africanos) e bem como a sua inter-relação com o mundo. Desta forma,

a solução proposta para superar a grande quantidade de línguas era defender o uso de uma única língua europeia como uma língua nacional porque as políticas africanas baseavam-se na política de uma nação, uma língua (MAKONI; MEINHOF, 2006, p. 192).

No âmbito profissional, a língua acompanha o desenvolvimento. Hoje, as nossas línguas africanas recebem um inúmero contributo lexical de estran- geirismos e empréstimos linguísticos provenientes na sua maioria da língua inglesa. O inglês é a língua do trabalho e isso não pode ser exceção à área policial. O policial dever ser (de fato) polícia e não parecer. Por isso a sua formação deve ser completa e integral por forma a atender às necessidades da profissão com competência e profissionalismo.

O trabalho da polícia exige ouvir muito, ver muito e falar o essencial. Não basta querer, é preciso agir aplicando na prática o conhecimento adquirido nos treinamentos de forma a poupar o sangue de inocentes que são mortos ou feridos devido a abordagens mal sucedidas ou mal executadas por parte da polícia. Como abordar um cidadão falante de língua diferente da sua? Como investigar um estrangeiro que fala uma língua desconhecida? Qual é o 'milagre' para executar com profissionalismo essa tarefa? As perguntas são provocativas para que possamos olhar o assunto "línguas" de forma mais séria e profunda possível.

Entendemos que a formação policial em nível de básico, médio e superior deve contemplar as línguas estrangeiras modernas como forma de prepará-los para os desafios da profissão em nível global. Nada impede que possam conhecer profundamente as suas línguas maternas africanas por forma a que possam ajudar na interpretação forense durante os interrogatórios policiais. Cidadãos que chegam a delegacia sem domínio da língua oficial podem receber apoio destes profissionais na tradução e 
interpretação das mensagens declaradas em Boletins de Ocorrência ou mesmo em interrogatórios.

A internacionalização do inglês caminha para uma "esperantização" (SIQUEIRA, 2011) ou ainda para uma língua global (CRISTAL, 2003), o que significa que, pelo seu envolvimento na economia mundial está sendo procurada e aprendida por todo mundo transformando-se assim, numa língua franca. A diferença com o esperanto reside no fato de o inglês ser uma língua natural, tal como Lyons (1987) advoga. Entendamos por língua natural qualquer linguagem desenvolvida naturalmente pelo ser humano de forma não premeditada. A língua natural se caracteriza pela flexibilidade, adaptabilidade, arbitrariedade, produtividade, heterogeneidade e possuir uma dupla articulação (LYONS, 1987).

Hoje em dia a mobilidade das pessoas de cidadãos falantes de língua inglesa é muito elevada. Muitos aeroportos, portos e rodoviárias colocam anúncios e informações dos passageiros em inglês e língua local (se existir). Desta forma, não se trata de favor colocar policiais e funcionários que falam línguas estrangeiras. Quanto mais tiver funcionários falantes de língua inglesa, mais utilidade terão para passar informações aos passageiros. O conhecimento do inglês é uma necessidade profissional.

A pesquisa nasce da reflexão da própria experiência como docente de língua estrangeira (língua francesa) em instituição policial, quando se observa a pouca valorização das línguas estrangeiras. Desta forma se levanta a seguinte questão de partida: Ao priorizar aulas práticas e disciplinas da área de Direito, as instituições de formação policial moçambicanas estariam preparando condignamente os futuros agentes no mundo globalizado? Avançam-se as seguintes hipóteses: as instituições de formação policial relegam a formação linguística para o segundo plano; a polícia pouco usa recursos linguísticos na sua atuação; a polícia precisa de dominar mais a prática do que a teoria.

A pesquisa objetiva valorizar a formação linguística como requisito fundamental para o desempenho da atividade policial. Especificamente, a pesquisa visa: discutir o conceito língua e explicar a sua importância na formação policial; indicar como o domínio de línguas estrangeiras ajuda positivamente no desempenho policial e com qualidade; apontar as metodologias que possam melhorar a qualidade de ensino e aprendizagem de línguas estrangeiras.

$\mathrm{O}$ artigo se divide em quatro seções: na primeira discute-se a noção de língua, contrapondo-se como instrumento profissional para atividade humana; seguidamente, desenvolveu-se questões inerentes ao ensino de línguas na área policial sempre focando na necessidade da valorização para que os agentes tenham êxitos na profissão. A terceira seção apresentou a metodologia para o ensino de língua estrangeira em contexto policial, levantando algumas estratégias e metodologias para uma aula dinâmica. 
$\mathrm{O}$ artigo termina com apresentação de vantagens de ter na corporação formada teórica e prática onde policiais conhecedoras de pelo menos uma língua estrangeira possam competir no esclarecimento de crimes e realizar todas as possíveis abordagens com sucesso.

\section{A língua: um instrumento profissional}

A LP é a única e exclusivamente língua oficial desempenhando todas as funções burocráticas do Estado. Quem não domina esta língua fica privado dos seus direitos fundamentais e o Estado pouco tolera os indivíduos que não dominam a língua oficial. Um caso excepcional é do artigo 49, do Decreto-Lei 30/2001 de 15 de outubro, que versa sobre as Normas de Funcionamento de Instituições Públicas que estipula o seguinte: "o cidadão que não saiba ou não possa escrever na língua oficial pode utilizar gratuitamente os serviços dum funcionário ou de qualquer outra pessoa para formular a sua sugestão ou reclamação por escrito". Esse aspecto para por aqui e não há outros desenvolvimentos por forma a melhorar a comunicação de indivíduos que não conhecem a privilegiada língua portuguesa. Em muitas leis e decretos moçambicanos pouco se faz alusão às Línguas bantu moçambicanas faladas pela maioria da população, incluindo a Língua Moçambicana de Sinais.

No exercício da maioria das profissões no mundo (principalmente em países desenvolvidos), a língua desempenha um papel importante, mas isso não é motivo para excluir outras línguas como inúteis. Para sermos mais concretos podemos dizer que apesar do inglês ser uma língua internacional e a mais falantes no mundo não significa que ela seja melhor que as outras. Desta forma se pode afirmar todas as línguas podem ser úteis desde que os usuários adotem políticas que favoreçam o uso pleno.

No que concerne ao trabalho da polícia, setores importantes como os aeroportos, os portos, as rodoviárias, as embaixadas, as ruas e avenidas exigem fortemente conhecimentos mínimos ou básicos de uma ou várias línguas estrangeiras. Um policial 'mudo' (que não conhece a língua do cidadão em causa) se torna vulnerável e não consegue atender as necessidades da profissão.

A língua, para Câmara Jr., é entendida como

[...] um sistema nítido e restrito de signos linguísticos, adquirido pelos homens de cada geração como uma herança e que eles espontaneamente contrapõem aos que usam outros grupos de homens (1989, p. 289).

\section{A língua}

[...] só existe como soma de múltiplos atos vocais individuais, porém nesses atos cada homem se serve de um sistema de elementos vocais que recebeu da sociedade em que vive (CÂMARAJR., 1989, p. 24).

Luft defende que o sistema "é coletivo, compartilhado por todos os membros da comunidade [...]" (2007, p. 14). Isso significa que as regras são moldadas no seio da comunidade linguístico que ao mesmo se interliga à cultura do mesmo. 
Para além de portar a farda ou uniforme, a arma, as algemas, o cassetete entre outros instrumentos, o/a polícia deve portar um instrumento pouco invisível e indispensável: o domínio da língua. A língua, seja verbal ou de sinais é extremamente importante na atividade policial que até pode superar em grande medida as algemas e a arma. A língua usada de forma correta pode neutralizar o suspeito na abordagem para além de conduzi-lo de forma humana, respeitando os Direitos Humanos até à Delegacia (português do Brasil) ou Esquadra (português de Moçambique). É na língua onde se tem os atos de fala locutório, ilocutório ou perlocutório desenvolvidos e discutidos com propriedade por Searle (1984) e Chomsky (2009). É na fala onde identificamos as imprecisões, as hesitações e outras marcas que facilitam a abordagem.

Os grandes eventos internacionais, como, exemplo, a Copa das Confederações, a Copa do Mundo, os Jogos Olímpicos e Paraolímpicos, os Jogos Pan-Americanos e outros eventos de caráter internacional necessitam indispensavelmente de policiais com algum domínio de línguas. $O$ trabalho realizado nas fronteiras, aeroportos, rodoviárias, portos e outros lugares de potenciais circulação de estrangeiros necessita fortemente de agentes da polícia bilíngues ou mesmo trilíngues.

Para Timbane, o ensino de língua proporciona conhecimentos teóricos e práticos que permitem ao policial esta- belecer um diálogo possível, concreto e exato que serve para abordar ou colher informações junto aos cidadãos (oralmente ou por escrito) de forma clara e sucinta. Entendemos que o

[...] fraco domínio das técnicas de expressão e de comunicação pode revelar a incompetência do agente. Isso contribui para o descontentamento da população e a descrença das autoridades policiais (TIMBANE, 2016, p. 69).

A ação policial busca indícios e evidências, estabelece a ordem e tranquilidade públicas, executa mandatos judiciais, fornece informações ao Ministério da Justiça e todas essas ações só podem ser possíveis através do uso da língua nas modalidades orais e escritas.

Concordamos com Silva Prates quando afirma que

[...] o estudo das línguas estrangeiras vem se tornando cada vez mais necessário para uma melhor qualificação de quem deseja ocupar melhores posições nas suas funções profissionais (2009, p. 241).

Mas é relevante apontar que para a presente pesquisa não focamos especificamente em cargos ou posições dentro da instituição, mas sim o uso desse conhecimento para o exercício da atividade em si.

Em todo continente africano,

[...] as línguas européias tendem a ser qualificadas como ferramentas indispensáveis ao desenvolvimento da África segundo o modelo científico-tecnológico ocidental [...] (RODRIGUES, 2011, p. 35).

Existe ainda a idéia segundo a qual o desenvolvimento de um país só é possível graças a língua européia, seja inglês, 
francês ou espanhol o que nenhum estudo já demonstrou. Em alguns momentos, os analistas econômicos esquecem o fato de que a língua é ao mesmo tempo cultura. E a língua só pode ser entendida dentro do contexto em que está inserida. Câmara Jr. mostra que,

[...] funcionando na sociedade para a comunicação dos seus membros, a língua depende de toda a cultura, pois tem de expressá-la a cada momento. É resultado de uma cultura global (CÂMARA JR., 1989, p. 21).

Já que a língua é um instrumento profissional, então é necessário que seja prioritária na formação policial. Com isso não se pretende colocar de lado as outras disciplinas curriculares, mas poderia se integrar as línguas em paralelo com as outras disciplinas acadêmicas. Isso passa pela formação em ensino de línguas para fins específicos, o que é uma especialização. As universidades pedagógicas não dão conta da formação de professores língua para fins específicos.

\section{O ensino de línguas na área policial}

Quando a língua do cidadão for diferente da língua da justiça urge a necessidade de intervir um intérprete. Ora, a Declaração Universal dos Direitos Humanos determina que

[...] todo ser humano tem direito, em plena igualdade, a uma audiência justa e pública por parte de um tribunal independente e imparcial, para decidir sobre seus direitos e deveres ou do fundamento de qualquer acusação criminal contra ele (Art. 10, UNESCO, 1998).
O direito a um intérprete é garantido apenas a nível do julgamento e não a nível das esquadras (delegacias) no contexto moçambicano. O processo inicia nas esquadras e a polícia não possui intérpretes para lidar com esta necessidade básica. Por outro lado, os Direitos Humanos e liberdades fundamentais devem ser garantidos e, se forem violados, pode ser tomada uma ação legal contra o Estado.

Para situar o leitor seria importante descrever de forma sucinta sobre como a polícia moçambicana está estruturada. A Polícia da República de Moçambique (PRM) se divide em 4 ramos a saber: (a) Polícia de Ordem e Segurança Pública; (b) Polícia de Investigação Criminal; (c) Polícia de Guarda Fronteira; e (d) Polícia Costeira, Lacustre e Fluvial. As unidades de operações especiais e de reserva são compostas pela Força de Intervenção Rápida; Força de Proteção de Altas Individualidades; Força de Operações de Combate ao Terrorismo e Regate de Reféns; Força Canina; Força de Cavalaria e, finalmente, a Força de Desativação de Engenhos Explosivos (TIMBANE, 2014).

A missão principal da polícia é de garantir a segurança e a tranquilidade públicas no território moçambicano. A presente pesquisa terá seu foco na formação dos ramos (a) e (b). Os agentes da polícia dos ramos (a) e (b) são formados nas seguintes instituições: Escola Prática de Matalane (Província de Maputo), Escola Prática de Dondo (Província de Sofala), Escola Prática de Nakitiri (Província de Nampula), Centro de Instrução de Cães-Polícia (cidade de Maputo) cujo nível será 
básico (TIMBANE, 2014, p. 15). Para a formação em nível superior, os agentes são formados na Academia de Ciências Policiais - ACIPOL (Província de Maputo) onde se formam oficiais da PRM. O ensino da língua inglesa em Moçambique inicia no sexto ano do ensino fundamental enquanto que a língua francesa inicia no décimo ano de escolaridade. Fica claro que:

[...] a língua estrangeira sempre representou prestígio. Quem domina uma língua estrangeira é admirado como pessoa culta e distinta. Tanto isso é verdade que a palavra estrangeira é comumente reservada para qualificar uma outra língua que conta com mais respeitabilidade que a materna de quem fala - por mais incrível que isso pareça à primeira vista (RAJAGOPALAN, 2003, p. 65 , grifo do autor).

Tanto no ensino normal como no profissional, o ensino de língua vem ganhando um espaço privilegiado no currículo escolar. Mas as escolas profissionais devem, pois, instituir-se como dinâmicas sociais locais, reconhecidas pela sua qualidade, desejadas pelas instituições e pelos mais dinâmicos atores sociais, cruzadas com 0 desenvolvimento social local mais vasto, capazes de proporcionar uma proposta formativa sólida e ampla, procurando escapar assim ao estigma de uma formação de segunda escolha (TIMBANE, 2016).

$O$ francês geral ou o inglês geral não interessam muito para fins policiais. É fundamental adquirir as noções básicas, mas é necessário avançar-se para aspectos mais específicos da profissão. Chomsky defende que "a pessoa que adquiriu conhecimento de uma língua interiorizou um sistema de regras que relaciona som e significado de determinada maneira" (2009, p. 63). Então a partir dessa base, o agente de polícia precisa avançar para temas e conteúdos da sua profissão, o que em francês é comumente conhecido como Français sur lês Objetifs Specifiques (FOS) ou English for Special Purposes (ESP). Segundo Moulhrons-Dallies (2008), a língua aprendida para fins específicos coloca o aluno no centro das atividades da aprendizagem e pedagógicas. Sobre estes assuntos vamos desenvolver na próxima seção.

A escola é o espaço formal onde, por meio de professores ou ainda de especialistas dotados de conhecimentos metodológicos e práticos, planejam-se e executam o processo de ensino e aprendizagem. Este processo é consciente, organizado tem objetivos e metodologias próprias que fazem com que o aluno adquira competências ou conhecimentos diversos. Neste caso, em que se fala de aprendizagem de uma língua, adquiri-se competências de expressão e de comunicação oral e escrita (TIMBANE, 2015). Para Almeida Filho:

[...] a aula de língua estrangeira como um todo pode possibilitar ao aluno não só a sistematização de um código linguístico que o ajudará a se conscientizar do seu próprio mas também a chance de ocasionalmente se transportar para dentro de outros lugares, outras situações, e pessoas. Esses clarões culturais conseguem às vezes marcar nossa percepção e memória de maneira indelével e para sempre (2015, p. 45).

No caso da formação policial, o ensino da língua francesa e da inglesa é tido como complementar e não como principal, como se o trabalho policial não exigisse a língua. É importante referir que "as 
línguas podem funcionar simultaneamente como instrumento de opressão e, por outro lado, como constitutivos de práticas de resistência cultural e política" (RODRIGUES, 2011, p. 31). Servem de opressores no caso em que um policial não consegue abordar um estrangeiro e nem mesmo consegue interrogá-lo, acabando por prender/algemar sem justa causa. As línguas podem oprimir quando os direitos de estrangeiros são violados devido ao desconhecimento da língua do cidadão estrangeiro por parte do agente da polícia.

Por outro lado, a língua pode servir de instrumento de resistência quando o policial obriga que seja o estrangeiro a aprender a língua do agente de polícia. Esta questão é polêmica, pois sabemos que

[...] muito embora o nacionalismo tenha desempenhado um papel na emergência das línguas na Europa, na África o letramento, em vez do nacionalismo, desempenhou um papel mais crucial na tarefa de trazer à tona a noção de línguas separadas (MAKONI; MEINHOF, 2006, p. 197).

Desta forma, a formação policial não pode garantir que o estrangeiro que vem ao país tenha a obrigatoriedade de aprender a língua do policial. Entendemos que deve ser a formação policial que garanta que seus agentes aprendam as línguas estrangeiras para permitir o exercício pleno da atividade profissional. O policial deve estar munido de conhecimentos que lhe permitam interagir com o estrangeiro, buscando ou confirmando informações diante de um suspeito seja ele nacional ou estrangeiro. Desta forma, interessa-nos discutir quais as meto- dologias que podem ser adotadas pela instituição e pelo professor de línguas.

O manual de ensino usado na formação de policiais é o mesmo utilizado nas escolas fundamentais. As instituições não possuem materiais do tipo dicionários, livros, filmes, CD, DVDs, jornais revistas e outros materiais de auxílio e apoio ao ensino. Desta forma, as matérias ensinadas serão uma repetição para os que estudaram o ensino médio das Letras e novidade para os que tiveram ensino médio Ciências. Significa que haverá poucos avanços no processo de ensino-aprendizagem e haverá limitações de toda ordem.

O ensino de línguas é opcional, o que significa que o cadete tem a oportunidade de escolher se prefere estudar inglês ou francês. $\mathrm{O}$ que tem acontecido é que muitos cadetes escolhem o inglês, deixando o curso de francês com pouquíssimos cursantes. Como se sabe,

[...] o estatuto social de uma língua nova e o imaginário a ela associado influenciam a aprendizagem, mesmo que se trate de um processo excessivamente individualizado. (MARTINEZ, 2009, p. 26).

Por isso que muitos alunos escolhem por razões do prestígio que esta tem em nível internacional.

Vejamos a seguir, alguns caminhos que se pode trilhar para um ensino de qualidade que se centra no aluno e que permita o uso da língua em contexto real. Entendemos que exatamente isso que um cadete a polícia pretende prender. $\mathrm{O}$ cadete quer saber como se diz pistola, algemas, continência, marcha lenta, qual é o seu nome, mostre-me a sua identidade, 
para onde vai, etc em língua estrangeira (inglês, francês, etc). São esses recursos que vão permitir o exercício da sua atividade profissional de forma plena.

Apoiando-se em Cuq (1991), Puren (1988), Germain (1993) e Bérard (1991), afirmamos que um ensino geral, com objetivos gerais e não específicos não pode alimentar a expectativa e as necessidades profissionais do cadete. Um ensino centrado em objetivos específicos pode, de certa forma, responder positivamente aos anseios da profissão.

\section{Metodologia para o ensino de língua estrangeira em contexto policial}

Segundo Moulhrons-Dallies (2008), tanto o FOS quanto o ESP devem ser pensados tendo em conta "as necessidades" dos aprendentes. Neste caso, o foco é para as prováveis situações de comunicação na área policial. O FOS e ESP têm seus desafios. Primeiro é que o professor deve dominar a área profissional do aprendente. No caso da polícia, o professor deve conhecer a terminologia policial de forma a ensinar aos seus alunos em língua estrangeira; segundo, o professor deve se preparar para responder as 'necessidades' dos alunos aceitando a entrada na sala de outros materiais que ajudem a aprendizagem dos cadetes.

É por essa razão que Rajagopalan (2003) defende que a linguística aplicada deve ser repensada por forma a ganhar a própria relação com teoria/prática, focan- do em objetivos mais precisos. O linguista leva-nos a refletir profundamente no que nele designa por savoir-faire. Significa que as nossas reflexões e ações em sala de aula devem sempre estar ligadas com a aplicação prática dos conhecimentos.

Não é momento de pensarmos no método tradicional, nem no método áudio-oral, nem no direto ou ainda no método audiovisual. Seria provavelmente mais visível apontarmos a nossa metodologia para a abordagem comunicativa ou da sugestopedia. A abordagem comunicativa, segundo Martinez,

[...] desloca o centro de gravidade na dupla operação que caracteriza a tarefa do aprendiz: trata-se não de aprender para depois comunicar, mas de ligar intimamente o aprender ao comunicar (2009, p. 72).

A Abordagem Comunicativa defende a aprendizagem centrada no aluno não só em termos de conteúdo, mas também de técnicas usadas em sala de aula. Desta forma, o professor deixa de exercer seu papel de autoridade, de distribuidor de conhecimentos, para assumir o papel de orientador (LEFFA, 1988; BÉRARD, 1991).

A língua é um conjunto de eventos comunicativos. Por essa razão no ensino deve-se evitar diálogos artificiais, elaborados para discutir pontos da gramática. A abordagem comunicativa prefere privilegiar a comunicação real em detrimento da competência gramatical. O que significa que os textos escritos não devem se restringir aos livros, artigos de jornal e de revista, mas também deve abranger todas as formas de materiais impressos, digitais e outras formas de 
expressão. A abordagem comunicativa desencoraja recortes de textos ou textos adaptados porque se assim for perde-se a autenticidade do documento.

Então, o trabalho policial é prático e exige agilidade do falante tanto na língua oral quanto na escrita. Trazer para sala de aula situações concretas da atuação policial é preparar ao futuro agente para que possa compreender quais os atos de fala, quais os tempos verbais e quais competências comunicativas que deve usar em situações reais de atuação.

Na perspectiva de Leffa (1988), o aspecto afetivo é visto como uma variável importante e o professor deve mostrar sensibilidade aos interesses dos alunos, encorajando a participação e acatando sugestões. $\mathrm{O}$ gráfico 1 resulta de uma pesquisa feita por Timbane (2013) quando pesquisou cobre o tipo de frases construídas pelos agentes de polícia numa abordagem a pé no Brasil. Portanto, observa-se no Gráfico 1 percentagens de frases interrogativas, imperativas, declarativas e exclamativas.

Gráfico 1 - Percentagem de tipos de frases construídas na abordagem policial

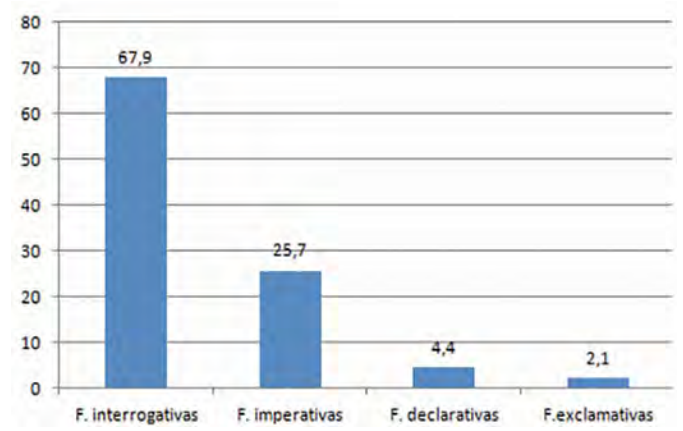

Fonte: Timbane (2013, p. 137).
O gráfico mostra claramente como o professor de língua estrangeira pode trabalhar em sala de aula. O estudo de Timbane (2013) revela que na área policial, os policiais utilizam mais frases interrogativas $(67,9 \%)$ e imperativas $(25,7 \%)$. Esses dados orientam o professor de língua estrangeira, que deve priorizar frases desse tipo nos exercícios orais e escritos nas aulas. É um dado importante, pois o planejamento das aulas deve incluir frases interrogativas. Os exercícios podem ser feitos oralmente e por escrito, pois o trabalho policial utiliza os dois tipos de línguas. Lembrando que aqui, não incluímos a língua de sinais.

Os valores semânticos que as palavras carregam devem ser aprendidas, pois a língua é ao mesmo tempo cultura. Na perspectiva de Câmara Jr.:

1) a língua é parte da cultura; 2) é, porém, parte autônoma, que se opõe ao resto da cultura; 3 ) explica-se até certo ponto pela cultura e até certo ponto explica a cultura; 4) tem não obstante uma individualidade própria, que deve ser estudada em si; 5) apresenta um progresso que é o seu reajustamento incessante com a cultura; 6 ) é uma estrutura cultural modelo, que nos permite ver a estrutura menos nítida, imanente em outros aspectos da cultura (1955, p. 58-59).

Só para exemplificar partindo dos argumentos de Câmara Jr. pode-se citar exemplos de: anelar (ato do realizar o casamento tradicional), ferrar (dormir), engarrafar (fazer feitiço para um indivíduo 'amar' o outro), cabritar (corromper ou fazer corrupção), mortar (perder um jogo) famar (ostentar, exibir-se). Então, estas unidades lexicais só são 
compreendidas na cultura da variedade do português de Moçambique. Por essa razão apoiamos a existência de moçambicanismos, brasileirismos, angolanismos e por aí em diante. Porque as variedades espelham a realidade sociocultural da comunidade linguística. Estas características léxico-semântica também ocorre em línguas estrangeiras. Desta forma, o aluno que aprende uma língua estrangeiras precisa conhecer nuances semânticos que a língua carrega para que não use inadequadamente certas palavras e causar mau-estar na comunicação.

Para Timbane (2013), a abordagem policial apresenta as seguintes características linguísticas: é contextualizada, é implícita, é redundante, não é planejada, apresenta-se de forma fragmentada e incompleta. Ela é pouco elaborada com pouca densidade informacional, com predominância de frases curtas e simples. Impossível fazer abordagem sem o uso de uma língua. A voz de prisão só existe se for transmitida através de uma língua. Então, essas estratégias comunicativas devem de certo modo ser ensinadas aos cursantes.

Por outro lado, a abordagem policial apresenta um vocabulário de menor densidade que responde prontamente ao momento interacional. O texto oral produzido na abordagem policial

[...] apresenta falsos começos, truncamentos, correções, hesitações, repetições, paráfrases, pausas, esclarecimentos, defesas e, sobretudo um fluxo discursivo que apresenta descontinuidades (TIMBANE, 2013, p. 138).
Num ensino cuja base é FOS ou ESP deve se trabalhar esses aspetos para que o cursante saiba como conduzir o seu discurso em língua estrangeira. Hoje em dia, temos muitos filmes de ficção científica, filmes policiais, filmes de ação em que os termos policiais e paramilitares são usados. Esses materiais podem ser considerados autênticos e podem ser organizados e utilizados em sala de aula.

São considerados documentos autênticos (em didática de línguas), todo material escrito, oral, visual, etc que não foi concebido ou fabricado para fins pedagógicos (GERMAIN, 1993; BÉRARD, 1991). O que significa que se compro jornal ou revista e os levo para a sala de aula a fim de utilizar como material didático, tenho um documento autêntico. Observa-se que o jornal não foi escrito para o uso na sala de aula, mas sim para informar aos leitores. O docente que adota o método comunicativo

[...] tem que conhecer bem a língua que está ensinando, inclusive suas questões gramaticais. A complexidade exige um tratamento e manejo menos simples e requer por parte do professor uma maior profissionalização e esforço (SILVA PRATES, 2009, p. 259).

A seguir, passamos a mostrar alguns princípios fundamentais para um ensino de língua comunicativo: as atividades de sistematização devem ser realistas e não materiais fabricados pedagogicamente. Essa atitude permite que os cursantes adquiram conhecimentos semelhantes (iguais) as que irão encontrar na vida real fora da sala de aula. As atividades em sala de aula devem simular situações 
reais de comunicação de forma a ligar a teoria à prática.

$\mathrm{Na}$ área policial, propõe-se que as simulações reflitam as diversas situações de patrulha, de abordagem, de investigação de crimes, de prestação de serviços aos cidadãos, como, por exemplo, explicar o caminho para cidadãos perdidos, dar palestra de educação cívica sobre como atravessar a rua ou prevenir acidentes de trânsito entre outros.

Propõe-se que o ensino não se restrinja apenas ao espaço sala de aula. Que hajam possibilidades de se realizar a aula fora do espaço habitual. Essa atitude "quebra o gelo" das metodologias anteriores que defendem o professor como o detentor do saber e que todo o processo está centrado nele. Visitar uma caserna, um armazém de armamento, centro de tiro, um setor da Esquadra ou da Delegacia é um bom passo para que os cursantes liguem a teoria da prática.

Todas estas atividades só poderão ter sucesso caso o professor faça um planejamento prévio de forma sistemática. $\mathrm{O}$ processo de ensino e aprendizagem da língua estrangeira (neste caso francês e inglês) deve favorecer e potencializar não só o desenvolvimento de competências orais e escritas (na expressão e na comunicação) que levem o aluno a compreender as diferentes manifestações dessa língua, mas também associar o desenvolvimento dessas competências a contextos socioculturais, a situações diversas do cotidiano e de sua vida profissional.
Já se disse que a língua é ao mesmo tempo cultura. Por isso qualquer interpretação ou tradução deve ter em conta a cultura. Existem elementos lexicais, gramaticais da língua "A" que pode não existir na língua "B". Chomsky nos lembra que:

[...] não interpretamos o que é dito em nossa presença simplesmente pela aplicação de princípios linguísticos que determinam as propriedades fonéticas e semânticas de um enunciado. As crenças extralinguísticas a cerca do falante e da situação desempenham um papel fundamental na determinação de como a fala é produzida, identificada e entendida (2009, p. 194).

Desta forma existem muitos subentendidos que se escondem na cultura. Dizer "casa”, por exemplo, a imagem que duas pessoas de culturas diferentes têm não é a mesma. Para alguém da cultura pode estar se referindo a um edifício de alvenaria com telhas e porta de vidro ou de madeira. Para mim, casa seria uma construção feita a estacas e caniço, coberto de palha de formato redondo e que fecha com um pano ou esteira. São duas realidades socioculturais para uma só palavra. Isso significa que o intérprete ou tradutor deverá ter em conta essas referências que a cultura e as tradições carregam.

Não se pode descartar a ideia de Rajagopalan quando afirma que

[...] as línguas são a própria expressão das identidades de quem delas se apropria. Logo quem transita entre diversos idiomas está redefinindo sua própria identidade. Dito de outra forma, quem aprende uma língua nova está se redefinindo como uma nova pessoa (2003, p. 69). 
Um dos grandes problemas no tratamento das imagens fixas é a interpretação e tradução. Observa-se que a interpretação de uma imagem está intimamente ligada a cultura de uma determinada comunidade linguística. Uma simples imagem pode ter várias interpretações. O uso de documentos autênticos: orais, escritos, icônicos e áudio visuais. $\mathrm{O}$ "uso de documentos autênticos na aula de línguas aproxima 0 aprendente à cultura da língua alvo" (TIMBANE, 2015, p. 254).

As instituições policiais da PRM possuem todo tipo de dificuldade na obtenção materiais didáticos para o uso na sala de aula. A razão é a que apresentamos anteriormente: as línguas estrangeiras? não são tidas como prioritárias. Desta forma, a comunidade educativa tem muitas dificuldades instrumentais e de recursos didático-pedagógicos, os quais impedem-na de conquistar a qualidade desejada. A polícia trabalha bastante com a linguagem. Até se pode afirmar categoricamente que a linguagem é que comanda o trabalho da polícia. Por exemplo, os agentes interpelam cidadãos e fazem um conjunto de perguntas de forma a averiguar um/a suspeito/a. Nessa atividade entra em jogo a importância da linguagem. Desta forma, pelas suas funções, "os agentes têm também a responsabilidade de zelar e de denunciar todos os atos e situações em que os direitos humanos de qualquer cidadão são violados" (THOMPSON; ALMEIDA, 2006, p. 48). Em nenhum momento a atuação da polícia deve-se basear em conhecimento popular.
A investigação deve se centrar na base legal que são os diversos instrumentos existentes, como é o caso da Constituição da República, O Código do Processo Penal, O Código Penal entre outros, mas sempre valorizando a linguagem como meio de comunicação. Cançado (2005) defende que os falantes nativos de uma língua têm algumas intuições sobre as propriedades de sentenças e de palavras e as maneiras como essas sentenças e palavras se relacionam. Por exemplo, se um falante sabe o significado de uma determinada sentença, intuitivamente, sabe deduzir várias outras sentenças verdadeiras a partir da primeira. Essas intuições parecem refletir o conhecimento semântico que o falante tem.

Esse comportamento linguístico é mais uma prova de que seu conhecimento sobre o significado não é uma lista de sentenças, mas um sistema complexo. Ou seja, o falante de uma língua, mesmo sem ter consciência, tem um conhecimento sistemático da língua que lhe permite fazer operações de natureza bastante complexa (CANÇADO, 2005).

\section{Vantagens de ter na corporação policiais especialistas em línguas estrangeiras}

Com a abordagem comunicativa pode-se colher mais vantagens que desvantagens. Se o orientador utiliza a abordagem comunicativa de forma consciente 
e sistemática, motivará constantemente os seus alunos dando-lhes oportunidade de aprender em contexto real. O policial sempre precisa de aulas práticas para que possa compreender melhor como se adaptar em situações adversas ao exercício das suas atividades. $\mathrm{O}$ documento autêntico retira $o$ aprendente do imaginário para situações concretas de comunicação. Os documentos permitem trabalho com diferentes gêneros textuais, permite compreender ou ainda falar com indivíduos de diferentes variedades da língua e respeita os "estilos de aprendizagem dos alunos" (TIMBANE, 2015).

A PRM deve envidar todos os esforços no cumprimento das normas que Constituição lhes imputa. É ela que garante a ordem e a tranquilidade públicas. Portanto, ter na corporação, agentes que conhecem pelo menos uma língua estrangeira é um ganho maior para: a) a investigação criminal e para a garantia da ordem e segurança, pois significa que a língua permitirá compreender e investigar estrangeiros em trânsito e residentes; b) abordagem policial: exige o domínio de uma língua para dar ordens, conselhos, orientações entre outras formas comunicativas; c) relações entre colegas de profissão e com estrangeiros; d) capacidade de resolver conflitos e contendas envolvendo estrangeiros; e) capacidade de cooperação com outras policias de países de expressão inglesa, francesa ou outras e; f) evitará a contratação de desconhecidos como intérpretes e tradutores nos interrogatórios e oitivas envolvendo estrangeiros em transito e residentes no território.

O domínio de línguas na corporação levantará o grau de iniciativa e de decisão altos. Isso porque se espera a autonomia plena no exercício da atividade. $\mathrm{O}$ que significa que em nenhum momento os policiais pedirão traduções nem interpretações quando lidam com sujeitos estrangeiros. Desta forma, o policial formado terá capacidade de assimilação e compreensão dos desafios que o estrangeiro passa no momento da abordagem. Com o domínio de línguas, o policial terá capacidade de mediar conflitos, trazendo sua sabedoria e experiência em prol da segurança pública.

Quem domina língua é sujeito a liderança em muitos casos, pois ele enxerga além daquele que é monolíngue. Nem sempre o policial tem à sua disposição todos os meios necessários a uma boa resolução de um determinado caso, por isso é importante que aplique seu nível de inteligência na busca de alternativas viáveis segundo o momento. A língua ajudará na materialização dessa competência.

A linguagem e a lei estão sempre intimamente ligadas. A lei não pode existir sem que haja algum meio de comunicação - a linguagem. É de extrema importância a integração da linguagem na justiça como instrumento de comunicação, de interpretação e de compreensão de mensagens orais e escritas. A Linguística Forense, (ou melhor, a Linguagem e a Lei) aplica conhecimentos teóricos 
e práticos da linguística na área do Direito. Sardinha (2009, p. 69) define a Linguística Forense como sendo a ciência que "se ocupa da análise da linguagem jurídica, de um lado, e do fornecimento de evidências linguísticas em processos judiciais, de outro."

Sardinha (2009) salienta que a linguagem jurídica descreve linguisticamente o valor das palavras, das frases e dos discursos em contextos do Direito desde as leis, decretos, estatutos regulamentos e outros. As evidências linguísticas surgem quando peritos são convidados pela justiça para decifrar e explicar as nuances de sentido linguístico de trechos, a autoria de voz, de discurso ou ainda características do idioleto de um suspeito ou acusado. No mundo atual, a justiça não dispensa os conhecimentos da linguística no levantamento de evidências em casos criminais.

$\mathrm{O}$ agente da polícia precavido utiliza conhecimentos da linguística para interrogar, para redigir documentos legais (autos, relatórios, inquéritos, etc) no sentido de mostrar as evidências positivas ou negativas de um caso suspeito ou de acusação. Mas não basta saber falar a língua, mas se deve conhecer profundamente as nuances linguísticas. Há um tabu segundo o qual quem fala uma língua (nem que seja sua língua materna) pode ser professor dessa língua. Outro tabu muito frequente em Moçambique é o de que se ensinamos uma criança a falar português em casa, terá mais sucesso na disciplina de português na escola.
Esses dois mitos mostram claramente que a aquisição e a aprendizagem são conceitos e realidades práticas diferentes. Mesmo tendo o português como primeira língua, os alunos não aprovam com nota máxima, isto porque a língua falada em casa é diferente da língua usada na escola. A língua estrangeira na formação policial em Moçambique traria maior qualidade no atendimento de estrangeiros assim como na investigação criminal.

\section{Conclusão}

Chegando ao fim deste debate, temos a sublinhar que o ensino de ensino de línguas é importante para o trabalho da polícia. Mas para isso é necessário que o cadete seja bem formado teórico e praticamente por forma a responder com prontidão das adversidades do mundo globalizado. Tal como Cristal (2003) demonstra na sua obra "O inglês como língua global" reforça a ideia de que nenhuma profissão sobreviverá sem essa integração. É preciso a) reconhecer a importância do multilinguismo no trabalho policial e na justiça; b) potencializar a formação humana com bases teórico-metodológicas na pesquisa, descrição e padronização das línguas africanas e de sinais; c) vencer as concepções e representações sociais, políticas nocivas à emancipação das línguas africanas e de sinas; d) valorizar as dinâmicas de promoção educativa em modelos bilíngues. 
Entendemos que pode haver injustiça se o cidadão for interrogado ou julgado numa língua desconhecida. Nenhum agente de polícia estaria (até hoje) em condições linguísticas para atender cidadãos falantes da língua de sinais, embora existindo cerca de $12,7 \%$ de população surda (TIMBANE, 2016). A língua de sinais moçambicana é pouco valorizada na justiça e isso já é um indício de injustiça. A injustiça inicia quando a coleta de provas é feita sem consideração da cultura, da língua e do contexto social em que o sujeito está inserido. Sem intérpretes forenses, estaremos andando "às escuras" desprezando preconceituosamente a realidade social do suspeito ou do sujeito a ser abordado. $\mathrm{O}$ reconhecimento das línguas bantu moçambicanas e da língua de sinais na justiça seria um primeiro caminho a seguir para uma justiça plena, mas isso passa pela adoção de políticas linguísticas.

A pesquisa comprovou a primeira hipótese, pois as instituições de formação policial relegam a formação linguística para o segundo plano. Mas aproveitamos mostrar a importância da formação policial de agentes da Polícia da República de Moçambique como forma de fornecer materiais que lhes permitam trabalhar com eficiência. Está comprovada a hipótese de que a polícia utiliza poucos recursos linguísticos na sua atuação, pois a maior parte dos policiais não possuem noções em língua estrangeira, fato os leva a recorrer a tradutores (maioria civis) nos interrogatórios policiais. Desta forma, a polícia precisa de dominar mais prática do que a teoria, pois nenhuma prática se torna eficiente sem o conhecimento da teoria.

Os professores de línguas nas instituições de polícia não possuem formação em FOS ou ESP. Esta situação faz com que não se avance mais na qualidade o ensino de línguas para objetivos específicos. Mas nada está perdido quando existe uma vontade política para que isso aconteça. Sendo assim, é possível remodelar o sistema de ensino investindo em materiais e na formação com qualidade de professores. Essa atitude culminará com a adoção de métodos que permitam uma educação mais prática que sempre está ligada à profissão. Por isso que falamos de FOS e ESP como caminhos mais adequados para uma formação mais profunda em qualidade. O policial deseja saber fazer e sobretudo na prática porque isso pode criar motivação e aprendizagem em contexto real. Tudo passa pela mudança de atitude de professores de línguas.

$\mathrm{Na}$ seção 3, colocamos o conceito sugestopedia, mas não desenvolvemos porque achamos que seria interessante tratá-lo de forma participar numa outra pesquisa. A metodologia sugestopedia vem da palavra 'sugestão'. A metodologia defende que o aluno deva ter a oportunidade de sugerir o que quer aprender. Que o professor não traga uma receita já pronta para sala de aula. A sugestopedia caminha nessa linha de força obrigando ao professor para que esteja pronto e 
bem preparado para que o aluno não sugira temas ou assuntos de pouco domínio do professor.

Respondendo à pergunta de partida podemos afirmar que a formação policial só terá profissionais linguisticamente preparados se apostar na formação multidisciplinar que inclui o ensino de línguas. Ao garantirmos uma formação policial de qualidade estamos garantindo uma atuação policial de qualidade e com respeito aos direitos linguísticos. Entendemos que as instituições de formação policial não poderiam relegar a formação linguística para o segundo plano. $\mathrm{Na}$ atuação policial sempre apela-se ao conhecimento linguístico para que os objetivos sejam alcançados com sucesso.

A pesquisa objetivou valorizar a formação linguística como requisito fundamental para o desempenho da atividade policial. Especificamente, a pesquisa discutiu o conceito língua e explicou a sua importância na formação policial. Mas também, a pesquisa indicou como o domínio de línguas estrangeiras ajudaria positivamente no desempenho policial e com qualidade. A pesquisa apontou algumas metodologias que poderiam melhoraria da qualidade de ensino e aprendizagem de línguas estrangeiras.

\section{The relevance of foreign language teaching in police training in Mozambique}

\begin{abstract}
The foreign languages have been the most sought after in the globalized world. The research launches a debate on teaching methodology and the importance of languages in police work in Mozambique. The research aims to discuss the concept of language and explain its importance in police training; Methodologies that can improve the quality of teaching and learning foreign languages in the police. Using a bibliographical method, the research concludes that there is a need for training of police officers in foreign languages so that they can respond with quality to the challenges of globalization, ensuring public order and tranquility.
\end{abstract}

Keywords: Teaching. Police Training. Foreign languages. Mozambique.

\section{Referências}

ALMEIDA FILHO, J. C. P Dimensões comunicativas no ensino de línguas. 8. ed. Campinas, São Paulo: Pontes, 2015.

BÉRARD, E. L'approche communicative: téorie et pratiques. Paris: CLE Internctional, 1991. v. 1.

CALVET, L.-J. Nouvelles perspectives sur les politiques linguistiques: le poids dês langues. Gragoatá, Niterói, n. 32, p. 55-74, $1^{\circ}$ sem. 2012.

CÂMARA JR., J. M. Língua e cultura. Letras, Curitiba, v. 4, p. 51-59, 1955. 
. Princípios de linguística geral: como introdução aos estudos superiores da língua portuguesa. 7. ed. Rio de Janeiro: Padrão Livraria Editora, 1989.

CANÇADO, M. Manual de semântica: noções básicas e exercícios. São Paulo: Contexto, 2005.

CHOMSKY, N. Linguagem e mente. Trad. Roberto L. Ferreira. São Paulo: Ed. Unesp, 2009.

CRISTAL, D. English as a global language. 2. ed. Cambridge: CUP, 2003.

CUQ, J.-P. Le français langue seconde. Paris: Hachette, 1991.

GERMAIN, C. Evolution de l'enseignement des langues: 500 ans d'histoire. Paris: CLE Internacional, 1993.

LEFFA, V. J. Metodologia do ensino de línguas. In: BOHN, H. I.; VANDRESEN, P. (Org.). Tópicos em lingüística aplicada: o ensino de línguas estrangeiras. Florianópolis: Editora da UFSC, 1988. p. 211-236.

LUFT, C. P. Ensino e aprendizado da língua materna. São Paulo: Globo, 2007.

LYONS, J. Linguagem e linguística: uma introdução. Trad. Marilda W. Averbug, Clarisse S. de Souza. Rio de Janeiro: Guanabarra Koogan S.A., 1987.

MAKONI, S.; MEINHOF, U. Linguística aplicada na África: desconstruindo a noção de língua. In: MOITA-LOPES, L. P. da. (Org.). Por uma linguística aplicada indisciplinar. São Paulo: Parábola, 2006. p. 191-214.

MARTINEZ, P. Didática de línguas estrangeiras. Trad. Marcos Marcionilo. São Paulo: Parábola, 2009.

MOULHRONS-DALLIES, F. Enseigner le français à des fins professionnelles. Paris : Didier, 2008.

NEVILLE, A. The politics of language planning post-apartheid South Africa. Language Problems \& Language Planning - JBPC, Amsterdã, v. 28, n. 2, p. 113-130, 2004.
NGUNGA, A.; FAQUIR, O. G. Padronização da ortografia de línguas moçambicanas: relatório do $3^{\circ}$ seminário. Col. Nossas línguas III. Maputo: CEA, 2011.

PUREN, C. Histoire des méthodologies de l'enseignement des langues. Paris: Nathan/ CLE Internacional, 1988.

RAJAGOPALAN, K. Por uma linguística crítica: linguagem, identidade e a questão ética. São Paulo: Parábola, 2003.

RODRIGUES, Â. L. A língua inglesa na África: opressão, negociação, resistência. Campinas, SP: Ed. Unicamp, 2011.

SARDINHA, T. B. Pesquisas em linguística de corpus com wordsmith tools. Campinas, SP: Mercado de Letras, 2009.

SEARLE, J. Mente, cérebro e ciência. Trad. Artur Morão. Lisboa: Edições 70, 1984.

SILVA PRATES, L. P. M. Uma análise sobre as praticas metodológicas no ensino de línguas estrangeiras. In: BURGEILE, O.; ROCHA, J. C. B. (Org.). Estudos e linguística aplicada: multilinguismo e ensino-aprendizagem de línguas. São Carlos: Pedro e João Editores, 2009. p. 241-262.

SIQUEIRA, S. Inglês como língua internacional, inglês como língua franca. In: LAGARES, X. C.; BAGNO, M. (Org.). Políticas da norma e conflitos linguísticos. São Paulo: Parábola, 2011. p. 333-354.

THOMPSON, R.; ALMEIDA, M. E. Manual de direitos humanos da mulher e da criança. Maputo: Wilsa Moçambique, 2006.

TIMBANE, A. A. Analisando o discurso policial na abordagem de suspeitos na via pública: estudo de caso. Revista Brasileira de Ciências Policiais, Brasília, v. 4, n. 1, p. 125-142, 2013.

A complexidade da conversão do oral para o escrito no interrogatório policial em Moçambique: estudo de caso. E-Scrita, Nilópolis, v. 5, n. 3, p. 1-17. set./dez. 2014. 
. A importância da fotografia no ensino do francês em Moçambique. Entretextos: Revista Científica de Pós-Graduação em Estudos da Linguagem, Londrina, v. 15, n. 2, p. 245-268, jul./dez. 2015.

- (Des)caminhos do ensino técnico e a complexidade do ensino em português em Moçambique. In: LIMA, B. de A. F. de. (Org.). Portuguesa na escola técnica: perspectivas e desafios. Rio de Janeiro: Dictio Brasil, 2016. p. 49-84.

UNESCO. Declaração Universal dos Direitos Humanos: adotada e proclamada pela resolução 217 A (III) da Assembléia Geral das Nações Unidas em 10 de dezembro de 1948. Brasília: UNESCO/Brasil, 1998. Disponível em: <http:/unesdoc.unesco.org/ images/0013/001394/139423por.pdf>. Acesso em: 12 fev. 2018. 